\title{
Problemas, debates y perspectivas de la Psicología Comunitaria en las Américas
}

\author{
Anuario del Grupo de Trabajo de Psicología Comunitaria \\ Congreso Interamericano Mérida, 2017, México
}

\author{
Editoras Invitadas1 \\ Sandra Estrada-Maldonado \\ Universidad de Guanajuato. México \\ María Malena Lenta \\ Universidad de Buenos Aires, Argentina.
}

Este número especial de la Revista Interamericana de Psicología constituye un nuevo espacio de encuentro entre las producciones del Grupo de Trabajo de Psicología Comunitaria, que se ha conformado en el marco de la Sociedad Interamericana de Psicología en el año 1991. Como continuidad de las presentaciones en el área durante los Congresos Interamericanos de Psicología, el Grupo de Trabajo se propone elaborar un anuario con el objetivo de contribuir al desarrollo de la psicología recuperando los debates y problematizaciones producidas a través de las conferencias, simposios, trabajos libres y otras presentaciones. A lo largo de los anuarios publicados en distintos formatos (revistas científicas, libros, CDs) y coordinados por diferentes equipos de editores/as, se pueden observar tópicos de problematización diversos desarrollados por múltiples grupos de trabajo y referentes del campo que aportan a las discusiones epistemológicas, metodológicas, éticas y políticas de la Psicología Comunitaria.

En esta oportunidad, el Anuario que presentamos cuenta con 13 artículos que surgen del Congreso Interamericano de Psicología desarrollado en 2017 en la ciudad de Mérida, México. Para iniciar el proceso de elaboración de este número especial de la Revista Interamericana de Psicología invitamos a todas las personas que realizaron diferentes tipos de presentaciones en el área en dicho evento, a que enviaran sus resúmenes. Luego de la invitación, recibimos 
en primera instancia 18 resúmenes extendidos que evaluamos, posteriormente, 13 de ellos fueron sometidos ya en modalidad de trabajo completo al arbitraje de la revista y completaron positivamente el ciclo de evaluación.

En función de dichos artículos, en este número especial de la Revista Interamericana de Psicología participaron 37 autores/as de Argentina, Brasil, Chile, México y Puerto Rico quienes abordaron, desde distintos enfoques, experiencias y propuestas, cuatro núcleos temáticos que son, desde nuestra perspectiva sintomáticos de los actuales escenarios en la disciplina. Estos ejes son: pobreza y exclusión social, problemáticas de género, salud mental comunitaria, así como políticas públicas y sociales. Todos ellos emergieron de los propios textos y reflejan tópicos relevantes de los debates contemporáneos de la Psicología Comunitaria de las Américas.

Probablemente la pobreza sea la temática más recurrente en nuestros países, volver a pensarla, sin embargo desde la óptica psico-socio-comunitaria nos permite revisar aristas que aunque distintas en sus geografías convergen en metodologías y análisis que destacan por mostrar dinámicas excluyentes en diferentes rostros, ya sea la migración, la ruralidad o la vida en situación de calle; los primeros cuatro trabajos (Ortiz-Torres \& Rodríguez-Cancel; Ferreira-Moura, Malherme-Barbosa, di Sousa-Martins \& da Cruz-Bomfim; EstradaMaldonado; Di Iorio) son justamente acercamientos que siguen optando por trabajar e incidir con las poblaciones fuera de los márgenes.

La categoría género se ha ido consolidando como un elemento central en casi cualquier análisis o problemática social y para la psicología comunitaria es también fundamental al pensar realidades e intencionar la implicación de esa construcción sociohistórica y cultural en las relaciones de poder entre hombres, mujeres y personas con identidades no heteronormativas. Los mundos en este eje van desde la salud mental en mujeres de comunidades en situación de pobreza, la organización de mujeres que transgreden mandatos tradicionales al ser ferroviarias y organizarse contra las violencias de género, hasta las historias de vida de personas trans y el machismo como una de las condicionantes de la desigualdad social (Barbosa-Nepomuceno \& Morais-Ximenes; Lenta, Longo \& Zaldúa; Rigueiral \& Seidmann; Almeida).

A partir de ahí, los siguientes textos nos sitúan más bien a un nivel macro desde el cual es posible pensar a lo comunitario en articulación con la política pública ya sea revisando aspectos de cultura organizacional, tensiones en programas sociales, o bien experiencias formativas y de acercamiento a la salud mental en contextos de pobreza, llevándonos incluso a pensar para el cierre, en el flujo y dinamismo entre nuestra disciplina y 
los programas sociales emanados de modelos neoliberales (Ortiz-Torres, Santiago-López, Cruz-Miranda, Nuñez-Maldonado \& Acosta-Ramírez; Opazo, Berroeta \& Guerra; Nabergoi, Albino, Maldonado, Garzón, Remesar \& Bottinelli; Castillo-León, Carrillo-Trujillo, CampoMarín, Barrera-Flores; Berroeta, Reyes, Olivares, Winkler \& Prilleltensky). salud mental y política pública son los dos últimos ejes en los que agrupamos los artículos incluidos en este volumen.

Destaca en la lectura transversal de los artículos la pluralidad de enfoques metodológicos presentes en este número pues hay trabajos desde la Investigación Acción Participativa pero también algunos asumiendo la lógica tradicional de investigación y/o con enfoque cuantitativo. No obstante, es el análisis de discurso, ya sea obtenido individual o grupalmente, la modalidad más frecuente de abordaje de los datos producidos en las investigaciones. Asimismo, en la visita a los artículos surgen interrogantes que nos convocan a seguir pensando en los desafíos de nuestra disciplina ¿Qué lugar ocupan nuestros trabajos en el abordaje efectivo de las problemáticas vinculadas a la desigualdad social de clase, géneros, etnias? ¿Cómo incorporar otros procesos de subalternización social en nuestras investigaciones e intervenciones? ¿Cómo comprendemos los alcances y límites de la transformación social de nuestras praxis? ¿Qué lugar ocupa la reflexividad autocrítica en nuestros procesos de investigación e intervención? ¿Qué tensiones encontramos entre nuestro quehacer y las políticas sociales?

Las personas lectoras de este volumen tendrán a su disposición una amplia gama de temas y enfoque epistémicos, así como también posibilidades metodológicas tanto de investigación como de intervención y reflexión teórica que hacen a la actualidad de los debates en el campo de la Psicología Comunitaria; se destaca, además, la cantidad y diversidad de material empírico en los 13 artículos que lo integran, lo que da cuenta de la vitalidad del campo.

Agradecemos a quienes participaron en este anuario por su esfuerzo y compromiso en las diferentes tareas, ya fuera para la elaboración de los trabajos como autoras/es, o para la lectura crítica realizada por quienes evaluaron, lo cual favoreció el enriquecimiento de los trabajos.

Finalmente, invitamos a las personas lectoras a acercarse a este anuario desde una mirada crítica con la expectativa de que contribuirá a abrir el diálogo, a generar nuevos 
interrogantes y a promover nuevas elaboraciones para el desarrollo de la Psicología Comunitaria. 